\title{
PERANAN PUBLIC RELATION DALAM MENINGKATKAN KREDIBILITAS INFLUENCER PADA UNIVERSITAS KEBANGSAAN BANDUNG
}

\section{Gita Eka Sila}

Fakultas Ilmu Sosial dan Sastra Universitas Kebangsaan

Email: gitaeka.sila@yahoo.com

\begin{abstract}
Abstrak
Penelitian ini memiliki tujuan untuk mengetahui seberapa penting peran public relations dalam meningkatkan kredibilitras influencer yang ada di universitas kebangsaan bandung. Metode yang digunakan dalam penelitian ini adalah metode kualitatif dengan pendekatan deskriptif. Sedangkan hasil yang diperoleh diketahui bahwa peran public relation dalam penelitian ini yaitu sebagai wadah dan fasilitator bagi mahasiswa yang memiliki potensi menjadi influencer di era 4.0 ini, dan diketahui terdapat faktor yang mendukung dan hambatan bagi public relation dalam proses tersebut.
\end{abstract}

Kata kunci: public relation, kredibilitas, influencer

\section{Pendahuluan}

Dalam kurang dari tujuh tahun kebelakang dunia media sosial terutama Instagram mengambil peran penting dalam mempromusikan produk. Dalam konteks tersebut bermunculah pihak ketiga yang disebut Digital Influenser. Digital Influenser ini adalah mereka yang mempunyai popularitas yang tinggi yang tidak mesti dari kalangan entertainer, artis maupun public figure melainkan mereka yang memiliki follower dalam akun pribadinya.

Kemajuan teknologi pada perkembangan komunikasi dan informasi telah mebuat peradaban manusia saat ini terutama internet adalah karya manusia yang sangat spektakuler (Nuruzzaman, 2018). Dalam terminoligi Microcelebrity yang merupakan cara baru dalam dunia online dimana seseorang meningkatkan popularitasnya dengan berbagai cara diinternet dengan menggunakan social media dengan menjadi selegram, vlogger, selegram dengan memanfaatkan situs jejaring sosial yang ada. Microcelebrity juga dapat dipahami sebagai suatu praktik dimana seseorang dianggap sebagai basis penggemar (fanbase), yang kepopulerannya dikelola melalui manajemen penggemar, dan presentasi diri seseorang secara hati-hati dikonstruksi sebagai bahan konsumsi orang lain" (Marwick, 2013). Terminologi lain untuk fenomena ini antara lain: key opinion leader (KOL), vlogger, selebgram, sosial media influencer atau untuk tema yang lebih spesifik seperti Beauty Gurus, Fashion blogger/vlogger, buzzer dan lain-lain. Kesamaan diantara terminologi tersebut adalah pengunaan platform sosial media/media digital dalam membangun fan base/followers (Evelina \& Handayani, 2018). 
Para digital influencer ini menjalankan fungsi promosinya dengan menggunakan metode word of Mouth (WOM). Kesuksesan fungsi promosi dengan menggunakan digital influencer ini telah di buktikan oleh survey statistik dari majalah forbes yang mengungkapkan 92\% konsumen lebih percaya kepada influencer dibandingkan dengan cara endorse tradisional dan iklan oleh selebriti, maka tak aneh jika digital influencer ini dapat menjalankan fungsi promosi lebih efektif melalui word of post.

Kehadiran media sosial memungkinkan PR untuk terlibat dalam peran manajemen strategis organisasi (McDonald \& Hebbani, 2011). Praktisi PR yang punya kompetensi menggunakan media sosial mendapatkan pengakuan dalam proses pengambilan keputusan organisasi atau perusahaan (Diga \& Kelleher, 2009).

Salah satu peran manajerial PR berkaitan dengan media sosial adalah keterlibatan dalam penyusunan peraturan media sosial untuk kalangan internal perusahaan. Peran sebagai pembuat kebijakan media sosial, menurut pandangan Breakenridge, memang belum terlalu populer namun hal tersebut mendesak untuk dilakukan: "once less known and vacant spot needs to be lled quickly" (Breakenridge, 2012).

Media sosial memang ibarat "pedang bermata dua" bagi perusahaan atau organisasi. Di satu sisi memang memudahkan berkomunikasi dengan publik baik itu internal maupun eksternal. Namun di sisi lain, karyawan kadang tak mempertimbangkan risiko penggunaan media sosial. Karena ketidakhati-hatian tersebut, karyawan mungkin mem-posting.

informasi sensitif atau menuliskan hal-hal yang buruk terkait perusahaan sehingga merusak reputasi perusahaan tersebut. Untuk mengantisipasi hal tersebut, perusahaan perlu memiliki kebijakan terkait media sosial.

Berdasarkan latar belakang tersebut penelitian ini dibuat, dengan rumusan masalah bagaiaman peran public relation dalam meningkatkan kredibilitas influencer pada Universitas Kebangsaan Bandung.

\section{Metode Penelitian}

Penelitian ini merupakan penelitian kualitatif yang dipandang sebagai bentuk kritik kepada positivisme dan para ahli menyebutkan sebagai post positivisme. Hal ini dikarenakan adanya pandangan bahwa hanya penelitian kuantitatif yang pemikirannya didasari oleh empirisme, idealisme, kritismem dan rasionalisme (Bungin, 2009).

Penelitian ini menggunakan metode penelitian kualitatif yang bersifat deskriptif. Menurut (Nazir, 2003) metode deskriptif adalah suatu metode dalam meneliti status sekelompok manusia, suatu objek, suatu set kondisi, suatu sistem pemikiran ataupun suatu kelas peristiwa pada masa sekarang.

Data dikumpulkan dengan menggunakan metode: Field research (penelitian lapangan), yaitu metode penelitian yang bertujuan mengumpulkan data primer dengan cara: Melakukan observasi terlibatdan melakukan wawancara langsung dengan beberapa informan yang dianggap dapat memberikan informasi sesuai dengan permasalahan yang diteliti. 
Analisis data merupakan hal yang perlu dilakukan untuk menguji kevaliditasan sebuah data. Analisis yang digunakan adalah analisis data kualitatif model Miles dan Huberman dalam (Iskandar, 2008) menambahkan bahwa analisis data model Miles dan Huberman dilakukan dalam empat (4) langkah yaitu : Reduksi data, Kategorisasi data, Penyajian datadan pengambilan kesimpulan (serong disebut tahap verifikasi).

\section{Hasil dan Pembahasan}

\section{A. Peran Public relation Dalam Meningkatkan Kredibilitas Influencer Pada Universitas Kebangsaan Bandung}

Seperti yang telah dijelaskan pada latar belakang masalah, yang menjadi pokok permasalahan penelitian ini adalah bagaimana peran public relations dalam meningkatkan kredibilitas influencer dan faktor-faktor apa saja yang menjadi penunjang dan penghambat yang ditemukan public relations dalam meningkatkan kredibilitas influencer. Dalam memperoleh hasil penelitian mengenai permasalahan diatas penulis melakukan wawancara mendalam dengan pihak universitas dan melakukan pengamatan atau observasi langsung, serta mencari informasi yang berkaitan dengan penelitian di universitas tersebut.

Teknik atau metode yang digunakan penulis dalam penelitian ini adalah wawancara mendalam dan observasi kepada universitas kebangsaan yang dianggap mampu memberikan informasi terkait penelitian penulis. Penulis mendapatkan penemuan-penemuan dari penelitian yang dilakukan yaitu: public relations dianggap sangat berperang penting dalam sebuah instansi pengelolaan pendidikan terutama sebagai building image di mata publik, karena public relations sudah ada sejak berdirinya universitas tersebut. dan alasan mengapa public relations penting bagi universitas ini, karena public relations yang membentuk citra universitas, mempublikasikan Program-program universitas dan memberi pengarahan kepada mahasiswa agar menjadi mahasiswa terbaik, itu semua menjadi tanggung jawab public relations sebagai jembatan antara universitas dengan publiknya.

Peran public relations dianggap sebagai orang yang ahli atau ujung tombak universitas. Dia orang yang mempunyai pengaruh penting terhadap perkembangan universitas. Karena public relations sendiri yang turun langsung membina mahasiswanya agar mereka betul-betul belajar dengan baik khususnya bidang komunikasi.

Seperti yang dijelaskan oleh Rektor Universitas Kebangsaan "Public relations dibantu oleh dosen dan mahasiswa, public relations disini tugasnya selain mengelolah sistem pemasaran internal dan eksternal universitas, juga mempunyai peran penting dalam meningkatan ekstrakulikuler mahasiswa dibidang penguasaan IT khususnya media sosial".

Peran public relations dalam proses pemecahan masalah. Pada peran ini public relations melibatkan diri atau dilibatkan dalam setiap managemen (krisis). Menangani krisis dalam universitas merupakan peran yang berkaitan dengan 
pengembalian nama baik universitas atau membangun identitas universitas setelah terjadinya krisis akibat penurunan eksistensi universitas. Peran public relations diperlukan agar krisis tersebut dapat terpecahkan melalui kegiatan komunikasi, dan dapat mengembalikan nama baik universitas. Sehingga universitas dapat terus berdiri kokoh dalam menghadapi persaingan global.

Seperti yang dijelaskan oleh ketua prodi ilmu komunikasi Universitas Kebangsaan Bandung

"Majunya teknologi informasi era 4.0 ini, berdampak pada kreatifitas kaum milenial untuk memperoleh penghasilan tanpa adanya keterikatan. Begitupun mahasiswa universitas kebangsaan ini harus bisa mengikuti perkembangan tersebut. Banyak contoh selegram-selegram di Instagram, youtuber pada platform youtube bahkan vloger-vloger pada youtube maupun instagram dan twitter. Peluang besar untuk anak muda jaman sekarang untuk bisa berkarya dan populer di media sosial".

Peranan public relations kemudian mengacu pada pelaksana teknis komunikasi dengan sistem pembelajaran ekstrakulikuler maupun pembelajaran di kelas yaitu melakukan kegiatan komunikasi atas dasar kebijakan dari universitas dengan berbagai strategi. Dengan peranan diatas inilah public relations Universitas Kebangsaan Bandung menjadikan acuan agar mahasiswa bisa berkembang dengan menguasai knowledge menjadi influencer bernilai positif di mata masyarakat.

Adapun peran yang dilakukan public relations Universitas Kebangsaan Bandung dalam meningkatkan kredibilitas influencer yaitu:

1. Menjaga hubungan dengan berbagai pihak

Menjaga hubungan harmonis dengan beberapa pihak dilakukan bertujuan untuk mendapat nilai baik influencer dan instansi atau citra yang baik di mata publik. Dalam membangun nilai baik influencer dan citra universitas tentunya hal yang perlu dilakukan adalah menjalin hubungan yang harmonis dengan beberapa pihak yang mungkin terkait dengan universitas. Agar pihakpihak yang mempunyai kepentingan terhadap influencer tetap percaya kepada universitas dan memberikan pemaparan tentang pentingnya memberikan informasi-informasi positif, public relations melakukan perannya dengan memberi penerangan kepada mahasiswa terkait media sosial yang aman dan memiliki peran dalam kehidupan masyarakat. Seperti yang dijelaskan oleh ketua fakultas Ilmu Komunikasi Universitas Kebangsaan Bandung

"Setiap influencer yang ada di media sosial tidak serta merta memberikan informasi yang positif, ada juga yang berkontribusi mengekspos hal-hal yang negative, semisal influencer yang menjual produk belum memiliki lisensi badan hukum yang sah untuk di konsumsi dan diperjual belikan. Dan terkadang membandingbandingkan dengan produk lain yang kualitasnya lebih rendah, dan tidak jarang influencer yang ada terkena pasal-pasal yang melanggar kode etik sebagai influencer". 
Hubungan baik juga harus dijalin dengan beberapa perusahaan yang menjadi mitra seperti halnya penjelasan dari salah satu dosen dari fakultas komunikasi "Influencer tidak serta merta hanya harus memiliki hubungan baik dengan instansi kampus melainkan dia harus tetap berhubungan baik dengan perusahaan yang menjadi mitra, walaupun secara operasional perusahaan memerlukan jasa influencer dalam mempromosikan produknya influencer pun sebaliknya (simbiosis mutualisme)".

2. Mempunyai karya inspiratif

Sebelum seseorang menjadi influencer, ada masa dimana dia harus mempunyai karya atau produk yang banyak menginspirasi penikmat media sosial. Banyak influencer yang mempunyai akun media sosial dengan karyanya berupa video-video covering lagu, film pendek, aneka tutorial dan sebagainya.

Karya inspiratif ini tidak mudah untuk dibuat, melainkan harus ada materi-materi yang harus dikuasai, seperti teknik desain grafis, teknik editing video, teknik pemotretan dan shoot foto. Peran public relation disini sebagai penyedia layanan pengetahuan agar mahasiswanya mempunyai karya yang menginspirasi.

Seperti halnya disampaikan oleh dosen Ilmu Manajemen Komunikasi

"Karya itu tidak harus berupa suatu yang ditulis dan dicetak bukan?, melainkan bisa berupa video maupun foto yang mempunyai nilai estetika dimata penikmatnya. Karya yang menginspirasi tercipta dari kreatifitas yang tinggi, untuk itu mahasiswa wajib menguasai ilmu-ilmu komputerais, seperti desain grafis, editing video, copywriting dan ilmuilmu lain yang menunjang kreatifitas untuk menghasilkan karya yang menginspirasi".

3. Aktif di media sosial

Hal pokok yang wajib dikuasai yaitu aktif dimedia sosial. Tidak akan menjadi seorang influencer apabila dia tidak aktif di media sosial. Perlu adanya konsistensi dan jadwal yang tepat untuk membuat konten. Sejalan dengan apa yang disampaikan Dosen Prodi Ilmu Komunikasi "sangat jelas, orang yang jarang update di sosial media tidak akan bisa menjadi influencer". Peran public relation ini untuk mengarahkan mahasiswa agar mampu menjaga konsistensi dalam membangun media sosial yang baik.

4. Mempunyai akun sosial media sesuai passionnya

Setiap orang memiliki bakat dan hobby berbeda-beda. Untuk itu tidak bisa setiap orang dibentuk untuk menjadi satu hal sesuai dengan keinginan orang lain. Ini penting untuk diperhatikan. Karena bakat dan minat seseorang akan menjadi ciri khas seseorang dalam menjalani hidupnya.

Ada istilah yang mengatakan "bekerja yang menyenangkan adalah hobby yang dibayar". Disitulah banyak generasi milenial mengambil alih. Ada yang suka dengan masak memasak mereka membuat video dan chanel youtube tentang masak dan seputar makanan, ada yang hobby dengan main game pun membuat sesuatu yang dia sukai begitupun dengan yang lainnya. Semua 
dikaitkan antara hobby dengan media sosial dan menjadikan itu sebuah pekerjaan yang membuahkan hasil.

Hal tersebut disampaikan oleh salah satu dosen prodi komunikasi "Penting untuk seseorang mengetahui minat dan bakatnya masing-masing hal tersebut bisa diketahui sedini mungkin. Tetapi tidak ada salahnya minat bakat diketahui ketika sudah menginjak remaja maupun dewasa. Karena dengan demikian seseorang bisa menggeluti bidang pekerjaannya sesuai keinginannya”. Disinilah peran public relations untuk membentuk karakter setiap mahasiswanya agar mempunyai karakter dalam kesehariannya.

\section{B. Faktor pendukung dan penghambat Public relations dalam Meningkatkan Kredibilitas Influencer Pada Universitas Kebangsaan Bandung}

Berdasarkan hasil uraian dari wawancara mendalam yang dilakukan, dapat diketahui peran public relations dalam meningkatkan kredibilitas influencer pada Universitas Kebangsaan Bandung tidak terlepas dari faktor pendukung dan penghambat:

1. Faktor Pendukung

Adapun faktor-faktor pendukung itu adalah :

a. Faktor internal

1) Sumber Daya Manusia (SDM) yang berkompeten

Sumber daya yang kompeten dimaksud adalah tenaga pendidik yang memang menjadi dosen dan dengan adanya workshop secara berkala yang menghadirkan praktisi. Keahlian public relations untuk menangani masalah yang muncul pun perlu ditingkatkan lagi, dibuktikan dengan kemampuan public relations menyesuaikan diri dalam membina mahasiswa dan dalam mengatasi masalah di Universitas Kebangsaan Bandung. Seperti penjelasan Ketua Program Studi Komunikasi "PR merencanakan penyelesaian serta mengambil keputusan-keputusan dalam membina mahasiswa dan membentuk menjadi influencer, karena hal itu semua sangat berpengaruh terhadap pribadi mahasiswanya itu sendiri”

2) Fasilitas pelayanan

Seperti halnya penjelasan diatas, instansi menyediakan layanan berupa ekstrakulikuler dan workshop secara berkala bersama praktisi langsung. Tidak hanya itu instansi menyediakan berbagai fasilitas diantaranya computer, jaringan internet, kamera dan beberapa alat lain sebagai media penunjang mahasiswa untuk menggeluti ilmu mengenai media sosial dan menjadi influencer. Pihak universitas khususnya bagian umum sarana dan prasarana menyatakan "berbagai macam fasilitas telah disediakan sebagai wujud kepedulian universitas terhadap perkembangan mahasiswa". 
3) Kerjasama AM (Agency Manager)

Adanya apresiasi dari pihak pengguna lulusan (Agency manager) menjadi daya dukung yang kuat bagi mahasiswa dalam menggeluti keilmuan komunikasi. Salah satu pengakuan yang di sampaikan oleh pengguna lulusan "kredibilitas influencer lulusan universitas kebangsaan sudah siap untuk dijadikan mitra kerjasama dalam menjual produk".

b. Faktor eksternal

Faktor eksternal berupa adanya respon positif dari masyarakat terkait program-program yang dijalankan public relations universitas kebangsaan bandung. Seperti penjelasan ketua prodi ilmu komunikasi "setiap tahun terus bertambah mahasiswa yang masuk ke fakultas ilmu sosial dan sastra, salah satunya dengan adanya program-program dan prodi ilmu komunikasi yang memang sangat diminati oleh kaum milenial sekarang".

2. Faktor Penghambat

a. Kurangnya kualitas SDM dalam mengelola media

Media komunikasi merupakan sarana yang digunakan oleh public relations untuk dapat menyebarkan informasi kepada masyarakat. Pengelolaan media terutama website yang ada di Universitas Kebangsaan Bandung masih kurang optimal. Hal tersebut dikarenakan kualitas SDM yang ahli dalam mengelola website masih kurang, tidak semua pegawai dapat mengelola media website. Sedangkan yang bisa menggunakan website hanya beberapa orang dan masih merangkap untuk mengerjakan pekerjaan lain, sehingga informasi yang ada pada website masih kurang.

b. Tugas menjadi overload

Salah satu hambatan dalam melaksanakan peran public relations adalah adanya tugas yang menjadi overload. Hal tersebut dikarenakan bagian kesekretariatan yang merangkap peran sebagai public relations mendapat tugas tambahan selain melaksanakan tugas dan pokok yang dimiliki bagian tersebut. Faktor eksternal.

c. Minimnya anggaran

Peran public relations akan berjalan dengan baik apabila didukung oleh sumber daya manusia serta adanya anggaran. Menurut staf keuangan universitas kebangsaan menjelaskan bahwa "belum adanya kedudukan public relations yang strategis dan terbatasnya anggaran untuk mendukung public relations, merupakan beberapa hambatan dalam pelaksanaan peran public relations di Universitas Kebangsaan Bandung”.

\section{Kesimpulan}

Penelitian ini memiliki kesimpulan bahwa peran public relation dalam meningkatkan kredibilitas influencer yaitu sebagai wadah dan fasilitator bagi mahasiswa yang ingin aktif di sosial media tetapi mempunyai penghasilan dari sosial media tersebut. Disamping itu kondisi tersebut merupakan peluang bagi universitas 
dalam membantu generasi milenial dalam menyalurkan kreativitas dan hobby kearah positif. Selain itu terdapat factor yang mendukung dan menghambat public relation dalam merealisasikan fungsinya. 
Gita Eka Sila

\section{BIBLIOGRAFI}

Breakenridge, Deirdre. (2012). Social media and public relations: Eight new practices for the PR professional. Pearson Education.

Bungin, Burhan. (2009). Penelitian Kualitatif. Jakarta: Prenada Media Group.

Diga, Marichris, \& Kelleher, Tom. (2009). Social media use, perceptions of decisionmaking power, and public relations roles. Public Relations Review, 35(4), 440442.

Evelina, Lidya Wati, \& Handayani, Fitrie. (2018). Penggunaan Digital Influencer dalam Promosi Produk (Studi Kasus Akun Instagram@ bylizzieparra). Warta Ikatan Sarjana Komunikasi Indonesia, 1(01), 71-82.

Iskandar. (2008). Metode Penelitian Kuantitatif dan Kualitatif. Jakarta: Gaung Persada Press.

Marwick, Alice E. (2013). Status update: Celebrity, publicity, and branding in the social media age. Yale University Press.

McDonald, Lynette M., \& Hebbani, Aparna G. (2011). Back to the future: Is strategic management (re) emerging as public relations' dominant paradigm? PRism, 8(1), $1-16$.

Nazir, Moh. (2003). Metode Penelitian. Ghalia Indonesia Jakarta. Bahasa Indonesia.

Nuruzzaman, Mohammad. (2018). Terorisme dan Media Sosial Sisi Gelap Berkembangnya Teknologi Informasi Komunikasi. Syntax Literate; Jurnal Ilmiah Indonesia, 3(9), 61-76. 